\title{
Evaluation of Q-T interval in healthy adult males
}

Safety and tolerability parameters were assessed during the phase1 clinical trial of an Investigational New Drug (IND). The assessment involves detailed clinical examination, electrocardiogram (ECG), and other system-specific tests. It takes into account vital signs and laboratory parameters. The 12-lead surface ECG reflects the complexity of evaluating the risks and the benefits of the IND. Today, this is of major concern due to the Q-T prolonging potential of some non-cardiac drugs (e.g., terfenadine, astemizole, cisapride, and macrolides). Some of these drugs have been withdrawn from the market. ${ }^{[1]}$ An independent International Safety Board has also suggested various ways for evaluation of cardiovascular data. ${ }^{11]}$

Q-T interval is the ventricular action potential duration, which is rate-dependent. Based on the variability in heart rate, the corrected Q-T interval (QT $)$ is derived by the Bazett formula. ${ }^{[1],[2]}$

One of the risk factors for Q-T prolongation and subsequent complications include concomitant treatment with drugs having pharmacokinetic/pharmacodynamic interactions (azole antifungals and macrolide antibacterials). Q-T prolongation caused by some drugs, for example, class Ia, IIIa antiarrhythmics depends on their plasma concentration (typeA adverse event). ${ }^{[3 \mid}$ For others, such as, antibiotics, antihistaminics, and prokinetics the relationship seems to be idiosyncratic (type-B adverse event)..$^{[3] .[4]}$

Asymptomatic Q-T prolongation is a useful marker of cardiotoxicity. It may lead to ventricular tachyarrhythmias, namely "Torsades de pointes" (TdP or "twisting of the points," referring to the beat-to-beat changes in the QRS-axis). A feature of TdP is pronounced prolongation of Q-T interval in the supraventricular beat preceding the arrhythmia. Therefore, TdP may cause syncope and degenerate into ventricular fibrillation, leading to sudden death. Sometimes, however, it is self-terminating. ${ }^{[1],[5],[6]}$

As no data on healthy Indian population were available to be taken as reference standard, this study was undertaken to evaluate the 12-lead ECG of adult, healthy, male human subjects housed under standardized conditions.

A total of 366 subjects between the ages of 21-40 years, were recruited from our volunteer data bank. Their weight was $>50 \mathrm{~kg}$ (but within the range of the LIC (Life Insurance Corporation of India) Height-Weight chart), heart rate (HR) 50-89 bpm, normal body temperature, respiratory rate (RR) 15-25 bpm (breath per minute), systolic blood pressure (BP) 100-130 mmHg and diastolic BP 50-90 mmHg. Informed consent was obtained as per ICH-GCP guidelines. Those who tested negative for drugs of abuse and had routine lab investigation values within normal range were housed in the department in groups of six on the previous day of the study. They were relaxed and provided standard food, but were asked to abstain from caffeine, tobacco, and alcohol at least $24 \mathrm{~h}$ before the vital parameters were recorded (BP, HR, RR and temperature). This was followed by ECG recording. Consistent operator technique was maintained by ensuring skin preparation, correct leads placement, subject position, and data acquisition practices.

ECG was recorded always between 7 and 9 a.m. with validated electronic device, 'ClarityMed-ECG100A' with paper speed $25 \mathrm{~mm} / \mathrm{sec}$, calibration $10 \mathrm{~mm} / \mathrm{mV}$. U-wave was considered in the case of bizarre TU-mergers. ECGs were read by a single independent observer. QT $\mathrm{T}_{c}$ was calculated by the Bazett formula (QT/R-R). Interpretation was based on lead-II as recommended by the European Agency for Evaluation of Medicinal Products (EMEA). ${ }^{[1],[2]}$

The enrolled subjects had age of $27.8 \pm 3.9$ years, height $163.7 \pm 6 \mathrm{~cm}$, weight $59.5 \pm 6.1 \mathrm{~kg}$, HR $71.40 \pm 9.14 \mathrm{bpm}$, systolic BP 115.07 \pm 6 and diastolic BP $73.32 \pm 7.22 \mathrm{mmHg}$. Results are presented in Table 1 with coefficient of variation range 3.81-12.81.

Normal QT ${ }_{c}$, studied in western population is less than $430 \mathrm{~ms}$ and $450 \mathrm{~ms}$ and is said to be prolonged if more than $450 \mathrm{~ms}$ and $470 \mathrm{~ms}$ in healthy, adult males and females, respectively. Absolute QT is of greater prognostic significance, and a value more than $500 \mathrm{~ms}$ (irrespective of gender) is of clear concern. Normal Q-T dispersion (difference between maximum and minimum HR) is 40-60 ms and over $100 \mathrm{~ms}$ is of concern. ${ }^{[1] .[2]}$ In our study, the mean $\mathrm{QT}_{\mathrm{c}}$ was $372.4 \pm$ $14.18 \mathrm{~ms}$.

Q-T interval is a surrogate marker for prediction of serious adverse drug event (SADE). However, the risk of TdP is not a linear function of Q-T interval or the extent of Q-T prolongation during drug treatment. Some authors have suggested the evaluation of Q-T dispersion as a predictor of risk. ${ }^{[1]}$ However, the difficulty in accurately measuring Q-T interval and the lack

Table 1

\begin{tabular}{|c|c|c|}
\hline $\begin{array}{l}\text { Parameters } \\
(n=366)\end{array}$ & Mean $\pm S D$ & $\begin{array}{c}95 \% \text { confidence } \\
\text { interval }\end{array}$ \\
\hline HR (bpm) & $71.40 \pm 9.14$ & $70.46-72.33$ \\
\hline$P(m s)$ & $92.52 \pm 10.24$ & $91.47-93.57$ \\
\hline QRS (ms) & $84.82 \pm 7.25$ & $84.07-85.56$ \\
\hline$P Q(m s)$ & $146.35 \pm 17.34$ & $144.58-148.13$ \\
\hline QT (ms) & $347.06 \pm 20.16$ & $345-349.13$ \\
\hline $\mathrm{QT}_{\mathrm{c}}(\mathrm{ms})$ & $372.39 \pm 14.18$ & $370.94-373.84$ \\
\hline QT/QT ${ }_{c}(\%)$ & $93.33 \pm 6.30$ & $92.69-93.98$ \\
\hline QT/R-R (\%) & $40.96 \pm 3.63$ & $40.58-41.33$ \\
\hline
\end{tabular}


of reliable reproducibility showed Q-T dispersion as a weak predictor of future arrhythmia ${ }^{|7|}$ Furthermore, careful scrutiny of pharmacokinetic properties of the IND is mandatory to enable meaningful comparisons between in vitro and plasma concentrations from preclinical studies. Plasma concentrations of the IND in humans should be considered along with apparent volume of distribution, metabolic pathways, and mode of elimination. Although not precisely known, the close relationship between dose and plasma concentrations implicate that Q-T prolongation is also related to dose. ${ }^{[2]}$

In the future, basic and clinical pharmacologists will have to address several issues about the reassessment of licensed medicinal products and development of new drugs. Furthermore, licensing a new non-cardiac drug with Q-T prolonging potential and, simultaneously, recommending additional studies may be justified when major innovation is achieved in existing therapies. Our present data may be helpful in evaluating the cardiotoxic potential of test medication.

P. Roy, M.U.R. Naidu, Y.S.N. Raju, T. Ramesh Kumar, P. Usha Rani, P. Usha Kiran, G. Venkat Ramana
Department of Clinical Pharmacology and Therapeutics, Nizam' s Institute of Medical Sciences, Panjagutta, Hyderabad. E-mail: murnaidu@yahoo.com

\section{References}

1. DePonti F, Poluzzi E, Montanaro N. QT-interval prolongation by non-cardiac drugs: lessons to be learned from recent experience. EurJ Clin Pharmacol 2000;56:1-18.

2. Wensing G, Kuhlmann J. Risk/Benefit evaluation from phase I data. In: Kuhlmann J, Mrozikiewicz A, editors. What should a clinical pharmacologist know to start a clinical trial (phase1 and II)? Klinische Pharmakologie. Clinical Pharmacology. W Zuckschwerdt Verlag Munchen-Bern. Wien. Vol.16. New York: Druck Augsburg Presse; 1998. p.15-24.

3. ljaz A. Khan. Clinical and therapeutic aspects of congenital and acquired LQTS. Am J Med 2002;112:58-66.

4. Usha Rani P, Naidu MUR, Ramesh Kumar T, Shobha U, Ajit Kumar. Tachycardia during cisapride therapy. Indian J Pharmacol 1994;26:233-4.

5. Roden DM. Drug-induced prolongation of the QT-interval. N Engl J Med 2004;350:1013-22.

6. Liu BA, Juurlink DN. Drugs and the QT-Interval-Caveat Doctor. N Engl J Med 2004:351:1053-6.

7. Shah BR, Yamazaki T, Engel G, Cho S, Chun SH, Froelicher VF. Computerised QT-dispersion measurement and cardiovascular mortality in male veterans. Am J Cardiol 2004;93:483-6.

\title{
Update Ayurveda '06
}

\author{
Date $\quad: \quad 22^{\text {nd }}-24^{\text {th }}$ November 2006 \\ Venue : Nair Hospital Auditorium, D- Block, College Bldg., \\ TN Medical College \& BYL Nair Ch. Hospital, \\ Mumbai Central, Mumbai - 400008.
}

The conference will include invited lectures from eminent scientists, research workers, academicians, ayurvedic and allopathic practitioners' as well as industry stalwarts. Last date for submission of abstracts ( 250 words) is $15^{\text {th }}$ September 2006. For registration form and further details please visit our website www.nair.edu

\section{For further information, please contact:}

\section{Dr. Supriya Bhalerao, Organizing Secretary - Update Ayurveda '06}

Dr. Sharadini Dahanukar Advanced Centre for Ayurveda Research, Training \& Services, Department of Clinical Pharmacology, TN Medical College and BYL Nair Ch. Hospital, Dr. AL Nair Road, Mumbai Central, Mumbai 400 008, INDIA.

Contacts: 91-22-23014713; Telefax: 91-22-23050347

Email: clinpharm@vsnl.net 